\title{
¿Cómo se debe leer a Kant?
}

Hace algunos decenios, salvo conocidas excepciones, se consideraba en Latinoamérica, y en especial en nuestra $\mathrm{Pa}$ tria, que la Filosofía era simplimente una disciplina de lujo, un elemento adicional de una sólicla cultura. Filosofar era un pasatiempo interesante, que podía realizarse de vez en cuanđo, pero que ningún significado tenía como disciplina medular. El pensamiento filosófico era contemplado como algo lejano, que se elaboraba en otros países, y que no tenía ninguna importancia para el clesarrollo cultural del país. A nadie se le habría ocurrido tomar a la Filosofía como meta máximbidelsw tetividade La Filosofía no era sinónimo de esfuerzbocontînuadoeylinfetódicoşode investigación penosa. Era más bien conversación fácil, adorno personal, discurso florido y vivaz.

Hoy el panorama es completamente distinto. En México y Argentina, hay ya hombres que dedican su vida al conocimiento filosóficamente enfocado. En nuestro Perú mismo, se empieza a ver toda la importancia de los estudios filosóficos, y se comprende por fin, que para que se logre una verdadera cultura, y por lo tanto un país con personalidad definida, es necesario atacar con decisión y energía los grandes problemas de la Filosofía. Se vislumbrá ya con cierta claridad, que Filosofía no es ad,orno de salón, sino esfuer- 
zo integral hacia una culminación de sentido. Se empieza a creer que hacer Filosofía no es hacer bonitos juegos de palabras, sino dedicarse intensamente al análisis de los grandes problemas que se plantea la humanidad, y basándose en las grandes tradiciones de la cultura, tratar de ofrecer los resultados del esfuerzo personal por resolverlos, en la medicla de las propias posibilidades. La Filosofía no es considerada ya como una inspiración literaria, sino como una conquista cientifica, tal vez menos segura que las conquistas de la Ciencia positiva, pero tan penosa y de tanta significación social como aquellas.

Influir en el desarrollo y crecimiento de esta nueva actitud es la finalidad del presente artículo.

Para ello hemos tomado un párrafo de la Crítica de la Razón pura,-libro filosófico poy excelencia-obra que según creemos es el mayor representante de aquella actitud que toma a la Filosofía como esfuerzo encaminado hacia logros científicamente fundamentados. Nuestra intención es mostrar, como un pequeño párrafo puede ser objeto de grandes dificultades y del tremendosaesflurizos.tYasobre todo, cómo en Filosofía roJ segpitedecpirocederconersapidez y abandono, sino que hay que someter el espíritu a una continuada tensión. Solo esta tensión y este esfuerzo, permiten adentrarse en el sentido de las grandes obras, y hacen posible ver sus aciertos, sus errores y sus posibilidades de superación. Y es que la Filosofía se ocupa de problemas de tal importancia, de un sentido tan profundo y fundamental para el hombre, que sería un verdadero desacato creer que se trata de una disciplina fácil y sin ninguna importancia.

El párrafo en cuestión es el primero de la introducción a la Crítica en su segunda edición, y es en nuestro concepto 
uno de los más importantes y profundos de todo lo que se ha escrito en Filosofia hasta el presente.

\section{Dice así:}

"No se puede dudar que todo nuestro conocimiento empieza con la experiencia; pues de otra manera, ¿por qué medios podría excitarse nuestro poder de conocer, si no fuera por medio de objetos que impresionan nuestros sentidos, y que en parte producen ellos mismos representaciones, en parte provocan en nuestra actividad cognoscitiva la tendencia de compararlas, unirlas o separarlas suscitando de este modo, la elaboración del material bruto de las impresiones sensibles que da por resultado un conocimiento de los objetos, que se llama experiencia?".

Por ser el primer párrafo de la Introducción, por las palabras que emplea, por la manera como desarrolla la cláusula, no se puede dudar que nos hallamos ante pensamientos fundamentales.

Lo primero que notamos es la afirmación de que todo nuestro conocimientotconienza côtla experiencia. Esta primera frase Jes gle thechoinum irechazordel idealismo (I ). En efecto si se acepta que el comienzo del proceso cognoscitivo, para tener lugar, deba comenzar con la experiencia, se niega de hecho que haya conocimiento independiente de ella, no en el sentido de creación que sobrepase toda experiencia, sino en el sentido de funcionar sin excitante previo, que no dependa de una propia ponencia subjetiva.

La afirmación ađemás-y este es uno de los caracteres más interesantes de la Filosofía kantiana-lleva su prueba

(1) Hay que tener en cuenta que los partidarios de la interpretación idealista de Kant, se basan fundamentalmente en la segunda edición. Este párrafo pues serviría de prueba contraria a dicha interpretación. 
o justificación. La segunda frase del párrafo nos hace ver que, si nos queremos explicar el comienzo del funcionamiento cognoscitivo, debemos suponer la existencia de objetos que impresionan nuestros sentidos. Nada funciona sin una causa o un estimulo. Aceptar que la facultad de conocer puede ejercerse por sí sola, sin recurrir a la experiencia sería aceptar un efecto sin causa, o por lo menos, si se aceptase la causa, tendría que ser una causa extraña y artificiosa, como por ejemplo, el poder creador de la consciencia, o la armonía prestablecida, etc. Mucho más fácilmente se explica el fenómeno, aceptando que hay estímulos externos que excitan con sus impresiones, nuestra facultad de conocer; hecho que por lo clemás, es evidente al sentido común.

En la tercera frase del párrafo, vemos, que Kant atribuye al conocimiento un toble aspecto, empírico y racional o supraempírico. El aspecto empirico, es la necesidad de que haya impresiones para que se suscite el poder de conocer. El aspecto racional estriba en la actividad del entendimiento, mediante la cual, las representaciones producidas por: estas impresiones son comparadas, unidas $y_{\text {separadas. }}$

Vemos en este reconocimiento de los dos aspectos del conocer, un logro definitivo de la Epistemología. Es tal vez uno de los aportes kantianos más firmes e importantes, y el que ha tenido más influencia en las posteriores escuelas epistomológicas. En esta frase se halla una de los síntesis más formidables de toda la historia de la Filosofía: la sintesis del empirismo y del racionalismo. En ella se nota a la vez la influencia de Hume y de Leibniz, y la superación de ambos.

A primera vista, parece que se hubiera terminado el análisis del párrafo que desde un comienzo, se presenta sustancioso, pero preciso y definido. Sin embargo al llegar. 
a la última frase, tropezamos con serias dificultades: "en parte provocan en nuestra actividad cognoscitiva, la tendencia de unirlas,....... y de esta manera, la elaboración del material bruto de las impresiones sensibles que da por resultado un conocimiento de los objetos, que se llama. experiencia".

¿Qué notamos de sorprendente en esta frase?

Parece haber una contradición con lo que se dijo al principio: "No cabe duda que todo nuestro conocimiento empieza con la experiencia".

En efecto si el conocimiento empieza con la experiencia, mediante la captación đe las impresiones sensibles, y luego el entendimiento interviene para elaborar estas impresiones y presentar un producto acabado, ¿cómo es posible que el conocimiento terminescon la experiencia?.

¿Es decir que después de la unión, comparación, separación, etc., de las impresiones sensibles, se volvería sobre ellas, y el conocimiento no hubiera logrado, sino volverlas a presentar, tal vez en otra forma, pero siempre en su multiplicidad conqietåcetindididal etras

Kant jay̧ásepretenidiólltalocosa:s de la lectura misma del párrafo se desprende esta certidumbre.

Sólo nos queda entonces, llegar a la conclusión de que Kant emplea la palabra experiencia en dos sentidos distintos.

El primer sentido vendría a ser el de representación concreta e individual (material bruto) y el segundo sería el de conocimiento logrado.

La primera clase de experiencia sería una experiencia de datos, de representaciones independientes de nuestra facultad racional. La segunda. sería una experiencia de productos, de construcciones, a base de los mismos, pero com- 
pletamente distinta a ellos. Entre ambas experiencias existiría la misma diferencia que hay entre los ladrillos con que se construye una casa y la casa misma. Esto puede comprobarse si se lee el primer párrafo de la introducción de la primera edición:

"La experiencia es sin duda el primer producto que produce nuestro entendimiento, en cuanto elabora el material bruto de las sensaciones".

La experiencia en el segundo sentido, que por ser el término del proceso cognoscitivo es el más importante, es pues un producto, una elaboración. La primera edición lo indica claramente. se?

¿Por qué Kant oscureció el senticlo de esta lacónica fra-

Nosotros vemos dos razones, En primer lugar Kant, después de terminar la corrección de la primera edición, corrección que estuvo sobre todo encaminada a hacer resaltar con más precisión la intervención del entendimiento en la elaboración de la experiencia- (en el segundo sentido) se dió cuenta que la nueya presentación de su obra, podia ser objeto de interpretaciones icealistas. Por esta razón quizo realzar el papel de qa parte no efaborađa, no construída, mejor dicho, no dependiente de nuestro entendimiento. Esto no está claramente expresado en el primer párrafo de la primera edición. Allí se dice simplemente que el primer producto el entendimiento es la experiencia en cuanto elabora el material bruto de las sensaciones. Pero puede que este material no sea de importancia para el conocimiento. Además pudiera muy bien ser que este material bruto fuera una creación del sujeto. En cambio al decir en la segunda edición, que nuestra facultad cognoscitiva es excitada por "objetos que impresionan nuestros sentidos" se da a entender con 
toda claridad que hay un aspecto del conocimiento que no depende del poder creador del entendimiento, sino que puramente y llanamente se "da" o se "impone" a la conciencia.

En segundo lugar, además de su posición no-idealista, Kant quizo acentuar, desde un principio, la diferencia entre las dos fuentes del conocimiento, a la vez que la relación entre ellas, cosa que muchas veces está imprecisamente indicađa en la primera edición, y que dió origen a que se creyera que la Crítica de la Razón pura era un tratado de Lógica. Por eso desde el primer párrafo, el pensador de Könisberg, dice que toda claridad que antes que actúe el entendimiento, ya hay algo que no es racional (en el sentido de que no es puesto por la razón), y de que este algo es tan fundamental al conocer como la actividad racional que posteriormente lo elabora.

De esta manera parece que la dificultad queda superada. Pero de inmediato surge otra tal vez mayor, como lógica consecuencia del análisis anterior. Si la palabra experiencia tiene Buim dobtee sentide, la patabra objeto, esencialmente ligada a la ppimera, debeoteners también un doble significado.

En efecto los objetos que impresionan nuestros sentidos, no pueden ser los mismos que constituyen la experiencia en cuanto impresiones elaboradas. Esto es innegable, pues cuando recibimos una impresión de un objeto, lo que se da a la conciencia no es el objeto en sí mismo, sino el objeto a través de la impresión.

Mejor dicho, objeto en el primer sentido, es decir en cuanto "impresiona nuestros sentidos" está fuera de la conciencia, es trascendente a ella, pues de otra maṇera no podría impresionarla. En cambio objeto en el segundo sentido, 
en cuanto es eli conocimiento elaborado, que se "llama experiencia" está dentro de la conciencia, es immanente a ella. Se deriva de unir, comparar y separar las impresiones. El primer objeto no depende de la actividad consciente. El segundo en cambio depende de ella, puesto que no se da sin la "elaboración del material bruto de las sensaciones".

Hay que anotar además, que el doble sentido de experiencia, aunque como dijimos, íntimamente relacionado con el doble significado de objeto, no le corresponde exactamente. En efecto la experiencia en su primera significación se refiere a la conciencia ingenua de las impresiones, no a los objetos que las producen. Estos jamás pueden presentarse de otra manera que a través de sus impresiones. En cambio en su segundo sentido la experiencia se refiere al segundo sentido de objeto. Experiencia en este caso es el conocimiento de dichos objetos, en cuanto elaboración del dato sensible hecha por el entendimiento. Entonces de aquí se sigue que para que haya experiencia no es necesario que haya objetos. Basta que haya "dato conciente".

Puede ahoraBridrsé coen cmaylox Iexiclencia. El primer

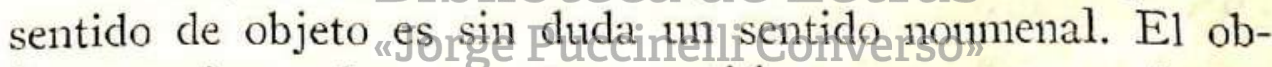
jeto que impresiona nutestros sentidos no es otro que la cosa en sí, el X general, que ponemos como substratum de toda representación en cuanto referida a una causa.

E1 segundo objeto es el objeto fenoménico, el objeto tal como se nos aparece, no tal como es en sí. El primero es el objeto trascendente, intangible e incognoscible, el segundo es el objeto tamizado a través de nuestras formas intuitivas y racionales.

El sentido general del párrafo se ha esclarecido, pero se ha complicado extraordinariamente. Su comprensión presupone tener noticia de una serie de puntos de la filosofía 
kantiana, que no se pueden conocer sin leer antes la obra entera.

Entonces, nos preguntamos ¿ Kant es un escritor complicadísimo, arbitrario, que no conoce las reglas ctel buen estilo?

Es innegable que la pregunta surge a menudo en la mente de todo lector de Kant. No solo en aquellos que lo abordan superficialmente, los cuales no podrán jamás librarse de esta convicción, sino también en los que quieren descubrir el sentido profundo de su pensamiento.

Hay que contestar que en parte, pero solo en una pequeña parte, es así. Kant no es un buen literato. Este es un defecto muy común de tos filósofos alemanes. Las frases de sublime belleza que sele conoce, se deben más que nada a la belleza de lo expresacho, no/de ta expresión.

Pero no solo se trata de que Kant es mal literato. En el fondo lo que pasa es que es en extremo difícil profundizar demasiado en un asunto y exponerlo en forma bella. Aunque Kant hubiera escrito con bellísimo estilo, seguramente que no hybiera conseguido druche más de lo que puda conseguir.

En efecto ¿ ¿omo expresar en forma sintética y precisa lo que Kant ha querido expresar en su primer párrafo?

Nos hemos dado cuenta de la finalidad que se persigue en él. Hemos anotado la descripción de todo el proceso cognoscitivo, de las exigencias explicativas que presenta su iniciación y del logro final de su activiclad.

Pues bien, si quitamos su doble sentido a la palabra experiencia, y a la palabra objeto ¿ cómo expresar en la misma forma sintética (y no hay que olvidar que la Crítica tiene más de 700 páginas) lo que Kant expresó en esa forma ambigua? 
El objeto en su primera significación podría reemplazarse por la palabra algo. Pero este término es demasiado general. No correspondería a la finalidad perseguida por Kant, que es acentuar ia diferencia de las dos fuentes cog. noscitivas, lo sensorial y lo racional. En efecto algo ptiede ser cualquier cosa, puede también ser un objeto independiente de la conciencia, como la voluntad divina, o la esencia platónica.

Podría entonces reemplazarse por Ente. Pero ente es una palabra que está cargada con demasiado Metafísica. Ente siempre ha significado lo que es, en sí, independiente de nuestra conciencia, pero que puede ser conocido racionalmente.

Si se tiene en cuenta sobre todo, que Kant luchaba contra la escuela wolffiana, filtimo rezago de la escolástica, y que en aquella época la palabra ente no tenía el significado menos especulativo que le atrubuyen los actuales sistemas metafísicos, se comprenderá perfectamente porqué Kant no puclo pensar jamás en tal palabra.

Lo mismo sucẹldeliołededadadra expensencia. ¿Cuál es el sentido que debemos conservali contul debe sen enriquecido con una nueva palabra?

Tremendo problema. Toda palabra del lenguaje vulgar brinda posibilidades infinitas de determinación. En el fondo la palabra experiencia, en su sentido más corriente y familiar, puede soportar una aplicación en muchos sentidos, pero no es suficientemente determinada por ninguno de ellos.

Hoy poseemos una palabra que podría substituir a la experiencia en su primer sentido, la palabra "dación". Pero Kant no hubiera podiclo usarla porque todavía no existía. Tampoco hubiera podido crearla, porque su creación es una consecuencia directa de la crítica de la Razón pura, por lo 
menos en el sentido en que la emplean los neokantianos, que es el único que podría reemplazar con ventaja al término empleado por Kant.

De cualquier manera que se enfoque el asunto, hay que reconocer que para dar mayor claridad y univocidad al famoso párrafo, hay que someterle a una total transformación, empleando términos que Kant no hubiera podido usar, debido a la época en que escribió su obra. Y aún así no podríamos estar seguros de haber logrado mayor claridad y precisión. Tendríamos para ellos que indicar minuciosamente el sentido que le diéramos a cada palabra, puesto que la mayor parte de ellas, estarían cargadas de múltiples y opuestas significaciones. Y de esta manera el párrafo se transformaría en un capítulo.

Si se quiere llevar el analisis hasta sus últimas consecuencias, puede verse todavía algunnos problemas fundamentales, como por jemplo la contradicción que significa la referencia a la cosa en si, cuando en realiclad todavía no se ha clado los medios de diferenciarla del fenómeno, la falta de especificación que-signffica no precisal a que conocimiento

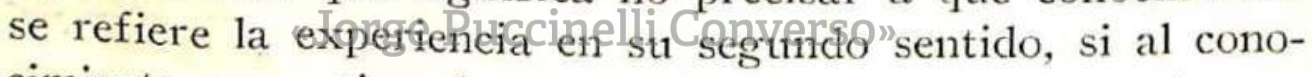
cimiento perceptivo (no en cuanto sensación pura, sino en cuanto captación de objetos) o al conocimiento científico objetivado, etc.

Pero con lo que hemos analizado, podemos ya darnos más o menos cuenta de lo que significa leer a Kant, o mejor dicho lo que significa leer seriamente cualquier obra filosófica, verdaderamente significativa.

Descle Juego que se nos puede hacer fuertes objeciones. Creemos que cuatro son las más importantes.

En primer lugar para poder leer a Kant de esa mane- 
ra hay que poseer ya cierto grado de cultura filosófica, inclusive en lo que respecta a la misma filosofía kantiana.

En segundo lugar el exceso de análisis interpretativo puede dar pábulo a una serie de convicciones falsas. La interpretación puede ser falsa, e influir poderosamente en toda la formación filosófica posterior.

En tercer lugar, es demasiado arriesgado, poner al lado de la interpretación meramente terminológica, una interpretación sicológica, en el sentido de tratar de adivinar la finalidad que tuvo el autor al escribir tal o cual frase.

$\mathrm{Y}$ por último el análisis demasiado profundo trae consigo el inmenso peligro de perder la visión unitaria del pensamiento del autor. Se gana en profundidad pero se pierde en panorama. $\mathrm{Y}$ casualmente el pensamiento filosófico debe procurar antes que nada la yisión sintética, la consideración de conjunto.

No cabe duda que estas objeciones tienen algo de verdad. Pero se disipan apenas se tiene en cuenta que lo que hemos querido indicar es sólo el mecanismo principal de la lectura de un textoifilosófico. Ell análisis detallado es la piedra fundamentalj con que se "construye"so la lectura de un libro de Filosofía. Pero no basta. La Filosofía es en sí tan complicada y tan llena de problemas, que estos se reflejan necesariamente hasta en el modo de leerla. Leer Filosofía, es ya en sí un problema.

A la primera objeción constestamos diciendo que todo libro importante de Filosofía debe siempre keerse de dos maneras. Una de ellas, debe ser rápida e intuitiva. La otra debe ser lenta y analítica, tal como lo hemos hecho con el primer párrafo de la Introducción.

Mediante la lectura rápida, podemos, tener una visión general de la obra, y comprender sus rasgos fundamentales. 
Aunque no la entendamos completamente, podremos extraer de ella los elementos suficientes para entender a fondo una lectura analítica, la que luego repes curtirá sobre nuestra prinitiva visión de conjunto, puliéndola, dándole forma sólida $\mathrm{y}$ estructurándola.

A primera vista podría parecer que la lectura intuitiva debería ser anterior a la analítica. Creemos sin embargo que no es así. Ambas deben ser a la vez. Cuando se empieza un libro de Filosofía, se đebe dividir el tiempo de que se dispone, en dos partes. En la primera mitad se puede leer rápidamente, tratando de compensar por intuición lo que no se puede comprender, y en la otra mitad se debe proceder a una lectura analítica de lo que se leyó primero.

Desde luego que enandor se haya terminado el libro en la forma intuitiva, apenas sechabrá lédo medio capitulo en la forma analítica. Pero ambas lecturas habrán ya creađo el vínculo necesario para tener una verdadera visión esencial de la obra. Además da lectura rápida nos habrá puesto en condiciones de distingtuir las partes esenciales de la obra,

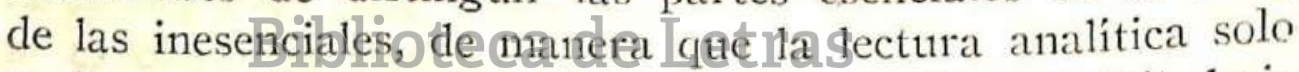
se lleve a caborcom lasipbineras. Essom efecto inútil decir que no toda la obra debe leerse en esta forma, ni mucho menos todo libro de Filosofía. El análisis clebe clirigirse sólo a lo fundamental. Pero eso sí, cuando es necesario ejercerlo, debe hacerse con verdadero empecinamiento. Es el último retoque de toda lectura filosófica, que pretenda hacer posible una comprensión con intenciones de llegar a una visión propia, y no quiera sólo dar los elementos para una mera repetición de los términos, como es tan frecuente en Filosofía.

Esto muestra indubitablemente las grandes dificultades de la lectura filosófica. Leer Filosofía no es leer novelas. Ni 
siquiera el estudio científico puede comparársele en esfuerzo y tensión espiritual. La Ciencia es dificultosa, pero su avance es lineal. Cuando se comprende una verdad se pasa de inmediato a la otra. En Filosofía no es así. La lectura debe ser radial, o mejor aún, concéntrica. No basta haber comprendido un párrafo para seguir. Muchas veces hay que volver sobre el mismo párrafo después de haber avanzado un buen trecho. $\mathrm{El}$ genuino pensamiento filosófico es eminentemente reflexivo, y constantemente vuelve sobre sí mismo. Esta es una de sus fuerzas y también una de sus grandes tragedias. Es el gran valor del filosofar y a la vez su propio límite. No es por otra razón, que Kant, uno de los más grandes filosófos đe todos los tiempos, tal vez el más grande, vuelve constantemente sobre sus pensamientos. Nadie mejor que él, intuyó esta estruotura peculiar del penmiento filosófico. No es otra seguramente la razón por la que comienza su obra con ideas que solo va a desarrollar con posterioridad (nos referimos al objeto noumenal). Como ha dicho muy bien un comentarista suyo, a la Crítica de la Razón pura, nopilede entrarse sin elnoumeno, pero una vez dentro de ella, no se puede conservar

La observación es veraz. Pero nosotros creemos que se puede generalizar. Toda obra filosófica tiene presupuestos necesarios para su comprensión que luego le son inútiles. Por esta razón es necesario leerla con una técnica especial, con una técnica que podría llamarse "concéntrica". Y la crítica de la Razón Pura es casualmente uno de los ejemplos más grandiosos de este proceder del filósofo. Es difícil entrar en ella, pero una vez que se cogen sus conceptos fundamentales, ¡qué armonía! ¡qué uniđad maravillosa!

La segunda objeción no es tan digna de consideración porque se refiere más bien a la capacidad del lector. Desde 


\section{$-\mathrm{I} 38-$}

luego, todo el mundo puede equivocarse. Es más, hasta tiene el derecho de hacerlo.

Lo que en realidad significa una dificultad seria, es la infinitud de todo proceso intepretativo. Si se prosigue con intensidad del análisis de cualquier párrafo profundo, puede llenarse miles de páginas, y se puede enunciar las hipótesis más diversas. En la interpretación que hemos presentado hay seguramente algunos errores, y muchas de nuestras afirmaciones serian rechazadas de plano por una serie de pensadores consagrados. Así un neokantiano por ejemplo, jamás aceptaría que la primera significación de la palabra objeto pueda ser la de cosa en sí. Pero nos consolamos, pensando que un realista estaría de acuerdo con nosotros.

Regresamos de nuevo aqu a la capacidad del intérprete. Si tiene verdadera capacidad filosófica, su interpretación será verídica, y el análisis será detenido a tiempo. justo en el momento en que brinde mayores posibilidades de comprender el sentido general de la obra. Ir demasiado lejos sería contudiproducente. de Letras

La tercena coibjeción soiblelliebensepr Eonada en cuenta como una advertencia, más que como una verdadera objeción.

La interpretación de la motivación del autor es a veces imprescindible. No hay que olvidarse que los libros son escritos por hombres, no por máquinas. $\mathrm{Y}$ sobre todo en Filosofía, en que los términos son equívocos, muchas veces no basta el análisis del mero término. Con gran frecuencia el sentido de una frase sólo puede ser captado si es referido a la intención. Y muchas veces este es el sentido que dá toda la clave de la solución. Hay ciertas frases que son incomprensibles sin conocer previamente la posición de su autor. 
Eso sí, el análisis đe motivos, debe ser prudente, y solo debe emplearse en último caso. Y sobre todo, lo que hay que evitar es la deplorable moda-que felizmente está ya pasando-de interpretar todas las frases de una gran obra por motivos no teóricos sino sicológicos o sociales. Tal genio escribió tạl frase porque era masoquista, o tal otro dijo aque1lo porque su alma era burguesa. Basarse en tales interpretaciones, para llevar a cabo una seria lectura filosófica, es desconocer los caracteres más elementales del conocimiento $\mathrm{y}$ de las personalidades orientadas hacia dicho valor. $\mathrm{Ha}$ cer una de aquellas ridículas interpretaciones es como querer bailar un trompo con lampa.

En cuanto a la última objeción, está ya en parte contestada a través de todo lo que hemos dicho. La doble clase de lecutra sobre todo, es lo que demuestra, que para un espíritu con verdadera potencia filosófica no existe el peligro de perderse en la inevitable maraña del análisis. La lectura intuitiva brinda los medios de llegar a una visión de conjunto.

Somos los prinietes cetereconbeer, sinr embargo, que la enorme complicaciónzragdap queipuede dlevarsun análisis profundo, trae consigo serios peligros. El más grande de ellos, es la pérctida del entusiasmo y de la fe.

Cuando recién se empieza a leer Filosofía, se práctica casi siempre el método intuitivo, y se logra llegar a visiones más a menos integrales, que a medida que vaya progresando el análisis, deben ir transformándose y coordenándose. Este es el momento peligroso. Cuando el estudiante realmente trata de llegar al fondo del asunto, y empieza un análisis prolijo de los textos que lee, es tal la cantidad de problemas que se le presentan, tal la infinitud de posibilidades, tal el mar de contradiciones y callejones sin 
salida que siente una sensación muy parecida al vértigo. Este vértigo del análisis filosófico, es a la vez embriagador y desesperante. A veces es tan intenso que hasta las sienes empiezan a latir y parece que fueran a reventar. Las antiguas concepciones se derriten como castillos de nieve, las visiones panorámicas se convierten en oscuros desfiladeros, las palabras empiezan a dar vueltas y hasta parece que el suelo se abriera bajo los pies.

Es entonces que faltan las fuerzas para seguir adelante. Cuando el cansancio y la laxitud, provienen del análisis filosófico, son pesados y dejan efectos duraderos, Es en estos momentos en donde hay que tener valor. Tal vez si se lee el párrafo una vez más o se ojea el libro en otra parte, se encontrará la palabra salvadora, que eche una luz directriz sobre el asunto. Entonces se recupera la visión perdida y el panorama surge de nuevo pero más amplio y bello que el anterior.

$\mathrm{El}$ que a pesar de todas estas dificultades, sea capaz de conservar su unidarb mental $\mathrm{Ye}^{\mathrm{n}} \mathrm{p}$ se deje aturdir por momentáneas dificultades, llegará a ser filósofo, es decir a adquirir una vision profunda y sistemática de la realidad, que le permita brindar un aporte más al acerbo cognoscitivo de la humanidad. Porque solo aquel que logre comprender a los grandes pensadores, y a las grandes obras, puede ser a su vez un pensador. $Y$ esta comprensión solo se logra con el análisis. El que tiene una visión panorámica puede más o menos darse cuenta de lo que es un sistema filosófico. Pero jamás llegará a penetrar su sentido ni a apoyarse en él, para dar aportes propios. El que quiere construir otro piso más, sobre una casa, debe conocerla hasta en sus cimientos para poderlo hacer. $Y$ es que la Filosofía más que labor de 
contemplación pasiva, es labor de penetración, de barreno. Por eso su problemática es fuerte y cerrada.

Somos los primeros en admitir que el método que propugnamos, no es absoluto, ni se puede aplicar mecánicamente. Creemos en la libertad conformativa de la persona humana. Todo hombre hace las cosas según sus propias posibilidades. Pero dentro de esta libertad de acción hay siempre una regla, una norma. $\mathrm{Y}$ esta regla se deriva más que de la persona que ejecuta la acción, de la naturaleza del objeto sobre el que se actúa. Tal es el presente caso. La filosofía es un fenómeno difícil de dominar. Es tan alto y tan espléndido, que solo se puede dominar tras ruda lucha. Así como una montaña coronada de nieves eternas, sólo se puede ascender con el trabajoso esfuerzo del paso firme y constante, así la cumbre del espíritu que se llama Filosofía solo puede ser alcanzada por el análisis, denso y profundo.

Creemos nosotros que los estudios filosóficos en el Perú, están yendo por este canino, penoso, pero seguro y lleno de promesas. Es nuestra esperanza que cada día se comprenda más y más la necesidad đe seguirlo con eterna decisión.

Biblioteca de Letras "Jorge Puccinelli Converso»

Francisco Miró Quesada. 